\title{
ALGUMAS REFLEXÕES E PERTINENTES PONDERAÇÕES, VIA ANÁLISE ECONÔMICA DO DIREITO, SOBRE OS BITCOINS E A SUA EVENTUAL UTILIZAÇÃO NA RECUPERAÇÃO JUDICIAL
}

\author{
Henrique Avelino Lana ${ }^{1}$ \\ Lucas Vinicios Cruz ${ }^{2}$
}

\begin{abstract}
Resumo
De forma acadêmica e construtiva, sem pretender esgotar o assunto, o presente artigo tem como objetivo realizar um estudo jurídico e econômico do bitcoin, que é a espécie de moeda virtual mais utilizada no mundo, mediante as ferramentas metodológicas da Análise Econômica do Direito, demonstrando como o uso de bitcoins nas transações realizadas pela sociedade empresária em recuperação pode reduzir os custos de transação e contribuir para uma recuperação judicial menos custosa, mais célere e mais eficiente, colaborando, ainda, para que a recuperação judicial cumpra os seus objetivos previstos no art. 47 da Lei n. 11.101/05, quais sejam, viabilizar a superação da situação de crise econômico-financeira do devedor, a manutenção da fonte produtora, bem como do emprego dos trabalhadores e dos interesses dos credores, promovendo, assim, a preservação da empresa e da sociedade empresária, sua função social e o estímulo à atividade econômica.
\end{abstract}

Palavras-chave: Bitcoins. Análise Econômica do Direito; Custos de transação.

\section{INTRODUÇÃO}

O mundo digital está em constante evolução. Cada vez mais, nos deparamos com novas invenções

\footnotetext{
${ }^{1}$ Doutor em Direito Privado pela PUC Minas. Professor de Cursos de Graduação e Pós-Graduação em Belo Horizonte/MG. Email: henrique@mpaladvogados.com.br
} 
tecnológicas que, até então, muitos acreditavam ser impossível. Smartphones cada vez mais modernos e computadores que cabem na palma da mão. Dia após dia, o mercado digital inova e surpreende a todos.

Destarte, com tudo ao nosso redor estando em constante evolução, com a moeda não poderia ser diferente. A moeda também evoluiu, iniciando uma era de moedas virtuais, chamadas bitcoins.

Em apertada síntese, bitcoin é uma forma de dinheiro, assim como o real ou dólar. Porém, difere-se destes por ser puramente digital e não ser emitido por nenhum governo. O seu valor é determinado pelos indivíduos no mercado. Logo, para transações online, pode ser a forma ideal de pagamento, pois é rápido, barato e seguro (ULRICH, 2014, p. 111).

Assim, o presente artigo tem como objetivo, realizar uma análise econômica e jurídica do bitcoin, para demonstrar que a sua utilização, pode facilitar as transações, reduzir os custos e maximizar os resultados, aumentando a eficiência da recuperação judicial, de acordo com os ensinamentos da Análise Econômica do Direito.

Para tanto, será realizada uma breve introdução ao estudo da Análise Econômica do Direito 3 , para então ser feita uma análise econômica do bitcoin, almejando, de forma construtiva e acadêmica, refletir se a sua utilização pode, ou não, ser benéfica na recuperação judicial.

Por fim, será demonstrado como as transações com bitcoin podem auxiliar a recuperação judicial a cumprir os seus objetivos, preservando a empresa ${ }^{4}$ e a sociedade empresária, ajudando-a a cumprir a sua função social e, então, superar a situação de crise econômico-financeira.

\footnotetext{
${ }^{2}$ Pesquisador bolsista do Grupo de Pesquisa Direito, Empresa e Desenvolvimento Social, do Centro Universitário UNA, Pósgraduando em Direito de Empresa pela PUC Minas. E-mail: lucas@mpaladvogados.com.br

${ }^{3}$ A redação e elaboração deste artigo pressupõe ter o leitor já prévio conhecimento do que representa a Análise Econômica do Direito e suas ferramentas metodológicas. Caso a intenção fosse descritiva quanto a AED, tornar-se-ia este artigo muito extenso e fora do seu foco. Logo, para o leitor compreender, de forma elementar, a AED, sugere-se: COOTER, Robert; ULEN Thomas. Direito \& Economia. 5a ed. Tradução: Luis Marcos Sander, Francisco Araújo da Costa. Porto Alegre: Bookman. 2010; LANA, Henrique Avelino. Dissolução parcial nas sociedades limitadas: Análise econômica sobre a inclusão do aviamento na apuração de haveres. Belo Horizonte: Arraes Editores. 2012; LANA, Henrique Avelino. Falência e Recuperação de Empresas: Análise econômica do direito. Belo Horizonte: Editora D’Plácido. 2017; MANKIW, Gregory. Princípios de Microeconomia. Tradução: Allan Vidigal Hastings. São Paulo: Cengage Learning. 2009; PATROCÍNIO, Daniel Moreira do. Análise Econômica da Recuperação Judicial de Empresas. Rio de Janeiro: Lumen Juris. 2013; PIMENTA, Eduardo Goulart; LANA, Henrique Avelino Rodrigues de Paula. Análise Econômica do Direito e Sua Relação Com o Direito Civil Brasileiro. In: Revista da Faculdade de Direito da Universidade Federal de Minas Gerais. n. 57. p. 85-138. Belo Horizonte: jul/dez. 2010; SALAMA, Bruno Meyerhof. O Que é "Direito e Economia”? In: TIMM, Luciano Benetti (Org.). Direito \& Economia. 2a edição. Porto Alegre: Livraria do Advogado, 2008; SZTAJN, Raquel; ZYLBERSZTAJN, Décio. Direito e Economia: Análise econômica do direito e das organizações. Rio de Janeiro: Ed. Campus. 2005.
} 


\section{BREVES PONDERAÇÕES ACERCA DA ANÁLISE ECONÔMICA DO DIREITO}

Conforme foi acima salientado, o principal objetivo deste artigo é realizar uma análise econômica do bitcoin e demonstrar que a sua utilização durante a recuperação judicial facilita as transações, reduz os custos de transação, maximiza os resultados e induz comportamentos, aumentando a eficiência da recuperação judicial.

Porém, para se chegar à melhor conclusão, faz-se necessário realizar uma breve explicação acerca da Análise Econômica do Direito, bem como a forma que esta se aplica ao Direito Empresarial e Falimentar.

A Análise Econômica do Direito (AED), também conhecida como Law and Economics, se trata de um método de estudo jurídico-econômico no que diz respeito à estruturação, formação, impacto e consequências da aplicação dos princípios da Ciência Econômica ao Direito. Pode ser definida como a aplicação da teoria econômica, em especial, seu método, para o exame da formação, estruturação e impacto da aplicação das normas e instituições jurídicas (RIBEIRO; GALESKI JÚNIOR, 2009, p. 53).

Conforme dispõe Eduardo Goulart Pimenta, "a Análise Econômica do Direito invoca a metodologia da ciência econômica junto à realidade fática do mundo jurídico" (PIMENTA; LANA, 2010, p. 98).

Embora a AED já tenha sido mencionada e estudada por outros estudiosos das Ciências Econômicas, como Adam Smith, ao estudar os efeitos econômicos decorrentes da formulação das normas jurídicas, e Jeremy Bentham, ao associar legislação e utilitarismo, ambos no século XVIII (ZYLBERSZTAJN; SZTAJN, 2005, p. 74), foi apenas a partir da década de 1960, que a AED ganhou forças para que Direito e Economia se unificassem (PIMENTA; LANA, 2010, p. 92).

Isto, pois, em 1960, Ronald Coase publicou a obra The Problem of Social Cost, iniciando a chamada Teoria dos Custos de Transação, obra que, em 1991, levou o autor a ser agraciado com o Prêmio Nobel de Economia.

O ganhador do Nobel explicou como a introdução de custos de transação na análise econômica determina as formas organizacionais e as instituições do ambiente social. A inserção de custos de Transação na economia evidenciaria a importância do Direito na determinação de resultados econômicos (PIMENTA; BOGLIONE, 2013, p. 268).

Importante mencionar, que além da obra de Ronald Coase, acima mencionada, há de se destacar também que Guido Calabresi, professor da Universidade de Yale, ao desenvolver sua obra Some Thoughts on Risk Distribution And Law of Torts, contribuiu fortemente para o avanço da AED.

Isto, pois, Calabresi demonstrou a importância da análise de impactos econômicos da alocação de recursos para a regulação da responsabilidade civil, seja no âmbito legislativo ou judicial. Com isso, sua obra

\footnotetext{
${ }^{4}$ Neste artigo, as terminologias empresa e sociedade empresária estão sendo usadas em consonância com o art. 966 do Código Civil, em que empresa é o objeto (a atividade), enquanto sociedade empresária é o sujeito.
} 
inseriu a análise econômica em questões jurídicas, apontando que uma análise jurídica adequada não prescinde do tratamento econômico das questões (ZYLBERSZTAJN; SZTAJN, 2005, p. 1-2).

Além de Ronald Coase e Guido Calabresi, há de se destacar que Richard Posner, com sua obra Economic Analysis of Law, bem como Henry Manne, George Stigler, Armen Alchian, Steven Medema, Oliver Wiliamson, entre outros, também contribuíram para o fortalecimento da pesquisa acadêmica acerca da Análise Econômica do Direito (ZYLBERSZTAJN; SZTAJN, 2005, p. 74).

Nesta senda, busca-se com o estudo da AED, elaborar, interpretar e aplicar a metodologia da ciência econômica às relações jurídicas, de modo a reduzir os custos de transação e alcançar a eficiência econômica.

Neste diapasão, eficiência, nas palavras de Bruno Salama, "diz respeito à maximização de ganhos e minimização de custos. Dessa ótica, um processo será considerado eficiente se não for possível aumentar os benefícios sem também aumentar os custos" (SALAMA, 2008, p. 55).

Logo, pode-se dizer que a AED tem como finalidade, a busca pela eficiência econômica.

No Direito Empresarial ${ }^{5}$, o custo de transação possui suma importância, pois é fundamental para o sucesso do empresário, já que é representado pelo valor monetário e pelo tempo despendido para celebrar as transações jurídicas, seja para planejá-las, seja para efetivá-las em seus efeitos. Pode-se dizer, assim, que o custo de transação é aquilo de que se necessita abrir mão, pagar, ou gastar tempo e dinheiro, para efetivação, manutenção, precaução, alienação ou cessão dos efeitos jurídicos de uma relação contratual (LANA, 2014, p. 29).

De acordo com Eduardo Goulart Pimenta (2010, p. 22-23), "custos de transação consistem naquilo que se precisa pagar ou de que se deve abrir mão para constituir, manter, proteger ou transferir os direitos e deveres decorrentes de uma relação contratual".

Logo, a eficiência consiste em diminuir ao máximo os custos de transação, para que, cada vez mais, sejam celebrados contratos e cada vez mais haja organização e acúmulo dos fatores de produção, resultando em maximização de riquezas, que são representadas pelo lucro.

Conforme preleciona Eduardo Goulart Pimenta:

A eficiência do Direito está em minimizar (ou hipoteticamente, acabar) com os custos de transação - mediante redução ou eliminação das dificuldades e gastos para contratação - de forma que, no exercício da empresa, haja uma maior quantidade e qualidade de trocas e relações jurídicas destinadas à organização dos fatores de produção. Sob um enfoque econômico a disciplina jurídica da empresa deve se preocupar em procurar reduzir ao máximo os custos que os empresários enfrentam para concretizar as relações jurídicas destinadas à organização dos fatores de produção (PIMENTA, 2010, p. 33).

Existem duas conotações importantes de eficiência conhecidas e utilizadas na AED: a eficiência de

\footnotetext{
${ }^{5}$ A Constituição da República Federativa do Brasil de 1.988 utiliza a expressão Direito Comercial (art. 22, I). Porém, o Código Civil de 2.002 trouxe a chamada Teoria da Empresa, motivo pelo qual a expressão Direito Empresarial, ou Direito de Empresa, passou a ser adotada.
} 
Pareto, aquela na qual a posição de A melhora sem prejuízo da posição de B, bem como a chamada eficiência Kaldor-Hicks, na qual o produto da vitória de A excede os prejuízos da derrota de B, aumentando, portanto, o excedente total (PINHEIRO; SADDI, 2005, p. 88).

A eficiência de Pareto significa que os bens devem ser transferidos de quem os valoriza pouco, em favor daqueles que mais os valorizam (SZTAJN, 2005, p. 76). Ou seja, em Pareto, a eficiência se dá nas transações que melhorem a situação de um agente econômico, sem piorar a situação de outrem. Segundo Eduardo Goulart Pimenta e Stefano Boglione, o conceito de eficiência para Pareto:

Pode ser traduzido no ponto de equilíbrio no qual não é possível melhorar a situação de um agente sem piorar a situação de pelo menos outro agente econômico, ou seja, a posição de uma parte A melhora sem a constatação de prejuízo da posição de uma parte B. Ou, ainda, mais precisamente, quando não há mudanças suficientes a satisfazer uma pessoa em melhor situação, sem deixar outras em situação pior. Em Pareto, o padrão ótimo de eficiência se dá quando os agentes econômicos têm acesso aos bens que mais valorizam, através de um sistema de trocas ou alocação de recursos (PIMENTA; BOGLIONE, 2013, p. 268).

Ainda sobre a eficiência em Pareto, Armando Castelar Pinheiro e Jairo Saddi explicam que uma alocação de recursos será Pareto eficiente quando "não há mudança que melhore a situação de um agente sem piorar a situação de pelo menos um outro agente". (PINHEIRO; SADDI, 2005, p. 120).

O ponto primordial da eficiência em Pareto é demonstrar que as transações podem ser tão eficientes ao ponto de que seria impossível realizar qualquer transação em que as partes sofreriam prejuízos.

Em contrapartida, a eficiência de Kaldor Hicks significa que as leis positivadas "devem ser utilizadas para causar o máximo de bem estar, em relação ao maior número de indivíduos, na medida em que os ganhos gerais compensem as possíveis perdas sofridas individualmente por alguns" (PIMENTA; LANA, 2010, p. 107).

Nas palavras de Eduardo Goulart Pimenta e Stefano Boglione:

Tem-se a Eficiência de Kaldor-hicks, portanto, quando o produto da vitória de A excede os prejuizos da derrota de $\mathrm{B}$, aumentando, portanto, o excedente total. Haverá um ganho real no bem-estar da sociedade quando a redistribuição da riqueza importe que os agentes econômicos não desejem retornar à posição original, embora ainda recebessem, em dinheiro, o valor correspondente ao acréscimo em seus bens e serviços (PIMENTA; BOGLIONE, 2013, p. 268).

Portanto, de acordo com a Análise Econômica do Direito, as partes devem tomar decisões que acarretem maior bem-estar, ou seja, devem agir em prol da eficiência, em consonância à eficiência de Pareto ou eficiência de Kaldor Hicks.

Seguindo esta linha de raciocínio, Irineu Galeski Junior e Márcia Carla Pereira Ribeiro salientam que o indivíduo deve aplicar a decisão que causar o maior bem-estar, tendo em vista que a AED tem por foco a busca do melhor bem-estar, da melhor alocação possível de bens, conduzindo ao bem-estar dentro dos limites (RIBEIRO; GALESKI JÚNIOR, 2009, p. 89).

Destarte, na recuperação judicial não é diferente, pois a Análise Econômica do Direito se preocupa em 
aplicar princípios das Ciências Econômicas às relações jurídicas patrimoniais, no intuito de reduzir os custos das transações e aumentar a eficiência da recuperação judicial.

Quanto à análise da falência e recuperação judicial sob a ótica da análise econômica do direito, Armando Castelar Pinheiro aduz:

Quando se define falência (ou recuperação de empresas), é comum nos atermos a definições jurídicas: trata-se de um processo de execução coletiva, meio de realização de direitos do credor. Entretanto, precisamos também nos lembrar de que o substrato que permeia o tema tem natureza econômica. Como lembra Thomas Felsberg, empresas insolventes são unidades produtivas exatamente iguais às solventes, com a exceção de que seus passivos se encontram desestruturados; fora isso, geram empregos, compram e transformam matérias-primas, vendem produtos acabados - enfim,produzem riquezas. Portanto, além da visão tradicional da execução coletiva, há que se considerar o assunto sob uma perspectiva mais voltada à análise econômica do direito (PINHEIRO, 2005, p. 208).

Noutro norte, Bruno Salama (SALAMA, 2008, p. 54-55) bem sintetiza as ferramentas metodológicas que podem ser usufruídas no estudo do Direito e Economia, inclusive quanto ao tema deste trabalho, quais sejam, escassez, maximização racional, equilíbrio, incentivos e eficiência.

Quanto à escassez, o Autor entende que, se os recursos fossem infinitos, não seria necessário equacionar a sua alocação. Assim, todos poderiam ter tudo o que quisessem, na quantidade que quisessem. Em relação à maximização racional, esta se refere à opção por escolhas que atendam aos interesses pessoais dos indivíduos. Assim, os indivíduos calculam para alcançar os maiores benefícios com os menores custos, levando ao processo de decisão marginalista, que quer dizer que, nos processos de tomada de decisão e realização de escolhas, os indivíduos só realizarão o próximo passo de uma atividade se os benefícios desta excederem os seus custos.

No que tange ao equilíbrio, este é o padrão comportamental interativo que se atinge quando todos os atores estão maximizando seus próprios interesses simultaneamente. Quanto aos incentivos, são preços implícitos, tendo em vista que os indivíduos procuram realizar escolhas que maximizem seus benefícios com a consequente redução dos custos.

E, por fim, o Autor cita a eficiência que, como já foi dito, refere-se à maximização de ganhos e minimização de custos. Assim, um processo será eficiente se for possível aumentar os benefícios sem aumentar os custos.

Especialmente em relação aos contratos celebrados pelo empresário ou sociedade empresária durante a recuperação judicial, a AED deve ser sempre utilizada, buscando-se reduzir a escassez dos recursos, optando a sociedade empresária por escolhas que atendam aos interesses pessoais da recuperanda, no intuito de alcançar maior benefício com o menor custo, bem como a eficiência no que contratar, com quem contratar, quando contratar e como contratar, ou seja, estes atos devem ser praticados de forma a buscar a eficiência.

E, por óbvio, nos contratos celebrados pela sociedade em recuperação, envolvendo bitcoins, este 
raciocínio deve ser igualmente aplicado, ou seja, as transações que contêm bitcoins devem se basear na Análise Econômica do Direito, tendo por objetivo a redução dos custos de transação e o aumento da eficiência na recuperação judicial.

Assim, como abaixo será demonstrado, durante a recuperação judicial, o administrador poderá não se opor, à inclusão de pagamentos em bitcoins como meio de recuperação, bem como a recuperanda poderá realizar transações com bitcoins, o que, pelas suas vantagens, acarretará, em tese, na redução dos custos e aumento da eficiência da recuperação judicial.

\section{ANÁLISE ECONÔMICA DO BITCOIN}

Com o avanço da tecnologia e o desenvolvimento do mundo digital, muito se ouve falar das criptomoedas e como elas vem sendo utilizadas de forma cada vez mais frequente nas relações jurídicas atuais.

Atualmente, existem cerca de 530 criptomoedas baseadas em sistemas criptográficos disponíveis para transações no mercado (SILVA, 2016, p. 37). Porém, a criptomoeda mais conhecida e utilizada nas relações jurídicas patrimoniais é o chamado "bitcoin", identificado, usando o pseudônimo de Satoshi Nakamoto, após este publicar o artigo intitulado "Bitcoin: A Peerto-Peer Electronic Cash System" (FERREIRA, 2014, p. 382).

Porém, de acordo com o economista Fernando Ulrich, a ideia da criptomoeda teria surgido com Wei Daí, em 1998, quando este expôs em um texto, as principais características do protocolo de uma criptomoeda e como ela poderia funcionar na prática. Inclusive, Wei Daí é citado por Satoshi em seu artigo como sendo a primeira referência em seu paper (ULRICH, 2014, p. 41).

Em relação a Nakamoto, Alexandre Pacheco da Silva (2016, p. 34) afirma que não há registros da existência de alguém de nome "Satoshi Nakamoto" antes do lançamento do Bitcoin. Silva menciona ainda que, no perfil de usuário de Nakamoto do fórum de criptografia, este se descreve "como sendo um homem de trinta e quatro anos que vive no Japão. Até hoje não há ninguém que conseguiu associar este nome a uma pessoa com estas descrições".

Conforme o economista Fernando Ulrich,

Precisamente no dia 31 de outubro de 2008, Satoshi Nakamoto publicava o seu paper, "Bitcoin: a Peer-to-Peer Electronic Cash System", em uma lista de discussão online de criptografia. Baseado na simples ideia de um "dinheiro eletrônico totalmente descentralizado e peer-to-peer, sem a necessidade de um terceiro fiduciário”, o sistema desenhado por

\footnotetext{
${ }^{6}$ Além da bitcoin, existem inúmeras moedas virtuais que também são utilizadas, tais como o Litcoin, a Novacoin, a Namecoin, a Anoncoin, e o Ethereum. Porém, todos os outros tipos de moedas digitais que não sejam bitcoin são denominados Altcoins (BARBOSA, 2016, p. 28-30).
} 
Satoshi surgia como um novo experimento no campo financeiro e bancário (ULRICH, 2014, p. 41).

A proposta de Satoshi Nakamoto foi à combinação de diversos conhecimentos técnicos espalhados na literatura da ciência da computação e da matemática para criar uma arquitetura de rede que permitisse com que equações matemáticas e técnicas criptográficas servissem a um sistema controlado por usuários, resultando, assim, no bitcoin (SILVA, 2016, p. 33).

Nesta senda, o bitcoin se caracteriza por ser uma moeda virtual, que utiliza protocolos criptográficos e algoritmos próprios para realizar transações através da internet, valendo-se de um controle descentralizado, ou seja, sem a interferência de alguma instituição financeira ou do Estado para regularizar sua comercialização.

Os bitcoins se compõem por uma carteira digital ${ }^{7}$, por um blockchain, que é um banco de dados que armazena todas as transações realizadas com bitcoins, e por uma rede peer-to-peer (ponto a ponto) de código aberto, motivo pelo qual não depende da intervenção de um terceiro (instituições financeiras) para intermediar as transações realizadas entre as partes.

Em relação ao blockchain, esta é uma espécie de livro-razão que contem o registro de todas as transações processadas com bitcoins, permitindo a todos os usuários a verificação da validade e autenticidade de cada transação. Ou seja, o blockchain é um banco de dados público, contendo o histórico de transações com bitcoins realizadas. Com isso, é possível assegurar que os mesmos bitcoins não tenham sido previamente gastos, prevenindo o problema do gasto duplo (ULRICH, 2014, p. 18; FERREIRA, 2014, p. 384).

As transações são verificadas por meio de um uso inteligente da criptografia de chave pública. Este mecanismo exige que a cada usuário sejam atribuídas duas "chaves”, sendo uma privada, que é como uma senha, e outra pública, que pode ser compartilhada com todos (ULRICH, 2014, p. 18).

Quando a Maria decide transferir bitcoins ao João, ela cria uma mensagem, chamada de "transação", que contém a chave pública do João, assinando com sua chave privada. Olhando a chave pública da Maria, qualquer um pode verificar que a transação foi de fato assinada com sua chave privada, sendo, assim, uma troca autêntica, e que João é o novo proprietário dos fundos. A transação - e portanto uma transferência de propriedade dos bitcoins - é registrada, carimbada com data e hora e exposta em um "bloco" do blckchain (o grande banco de dados, ou livro-razão da rede Bitcoin). A criptografia de chave pública garante que todos os computadores na rede tenham um registro constantemente atualizado e verificado de todas as transações dentro da rede Bitcoin, o que impede o gasto duplo e qualquer tipo de fraude (ULRICH, 2014, p. 18).

Segundo Ferreira (2014, p. 384), para começar a usar bitcoins, os usuários precisam fazer o download de um software ${ }^{8}$ livre e de código aberto. Após comprados, os bitcoins são posteriormente armazenados em uma

\footnotetext{
${ }^{7}$ Carteira é um segundo arquivo no qual os dados do arquivo bitcoin serão armazenados. Por meio da carteira, o usuário poderá realizar transferências de bitcoins para outras carteiras. (SILVA, 2016, p. 43)

${ }^{8}$ Este software necessário para transacionar no sistema Bitcoin é conhecido de forma ampla como bitcoin client (SILVA, 2016, p. 43).
} 
carteira digital no computador do usuário.

Além disso, os bitcoins podem ser obtidos mediante mineração, que segundo Tatiana Cassab Barbosa, é o "processo feito por um computador para solucionar uma equação matemática que, uma vez solucionada, irá gerar um número fixo de moedas digitais" (BARBOSA, 2016, p. 27).

Além da mineração, os bitcoins também podem ser recebidos como forma pagamento ou adquiridos pela compra de terceiros ${ }^{9}$.

Sobre a obtenção de bitcoins, Tatiana Cassab Barbosa explica que:

Para obter bitcoins, um indivíduo pode "minerar" estas moedas, ou seja, por meio de um programa de computador que soluciona um problema matemático, o individuo pode obter estas moedas, bem como obter mediante a compra e venda destas realizadas em casas de câmbios especializadas ou mesmo diretamente com outros indivíduos. Devido às características, qualquer um pode adquirir estas moedas (BARBOSA, 2016, p. 262).

Quanto à mineração, os mineradores são premiados com bitcoins recém-criados por contribuir com força de processamento para manter a rede e por verificar as transações no blockchain (ULRICH, 2014, p. 19-20).

Importante destacar que existe um número limitado de bitcoins que poderão ser minerados pelos mineradores. O limite máximo é 21 milhões de bitcoins. Neste sentido, Fernando Ulrich aduz que

O Bitcoin foi projetado de modo a reproduzir a extração de ouro ou outro metal precioso da Terra - somente um número limitado e previamente conhecido de bitcoins poderá ser minerado. A quantidade arbitrária escolhida como limite foi de 21 milhões de bitcoins. Estima-se que os mineradores colherão o último "satoshi", ou 0,00000001 de um bitcoin, no ano de 2140. (...) Uma vez que o último "satoshi" tenha sido minerado, os mineradores que direcionarem sua potência de processamento ao ato de vrificação das transações serão recompensados com taxas de serviço, em vez de novos bitcoins minerados (ULRICH, 2014, p. 20).

Assim, conforme se busca refletir, e sem pretender esgotar o assunto, utilizar bitcoins nas transações realizadas pelo empresário durante recuperação judicial pode ser mais benéfico para a recuperanda e seus credores, tendo em vista que poderá, também, ser uma alternativa para reduzir os custos de transação e maximizar os resultados, alcançando maior eficiência na recuperação judicial.

\section{A previsão normativa do bitcoin}

O bitcoin, como já explicado, se trata de uma moeda virtual, que utiliza um sistema "ponto a ponto" para realizar transações, não precisando, portanto, de um terceiro intermediário. Além disso, as transações são feitas via internet, em um sistema próprio do bitcoin.

Entretanto, atualmente, ainda não existe nenhuma legislação nacional que regula o uso de bitcoins ou

\footnotetext{
${ }^{9}$ De acordo com Alexandre Pacheco da Silva (SILVA, 2016, p. 37-38), atualmente, 59 empresas oferecem ambientes de comercialização em que se pode realizar a compra e venda de bitcoins.
} 
moedas virtuais.

Destaque-se, que não há que se confundir a incidência da Lei n. 12.865/13, que regula o uso de moedas eletrônicas, que são diferentes das moedas virtuais (bitcoins) (BARBOSA, 2016, p. 310).

Assim, para evitar confusões entre as terminologias, em 19 de fevereiro de 2014, o Banco Central se pronunciou acerca da distinção entre a moeda eletrônica prevista na Lei n. 12.865/13 e a moeda virtual. Desta forma, constou no Comunicado n. 25.306 de 19 de fevereiro de 2014:

O Banco Central do Brasil esclarece, inicialmente, que as chamadas moedas virtuais não se confundem com a "moeda eletrônica" de que tratam a Lei no 12.865, de 9 de outubro de 2013, e sua regulamentação infralegal. Moedas eletrônicas, conforme disciplinadas por esses atos normativos, são recursos armazenados em dispositivo ou sistema eletrônico que permitem ao usuário final efetuar transação de pagamento denominada em moeda nacional. Por sua vez, as chamadas moedas virtuais possuem forma própria de denominação, ou seja, são denominadas em unidade de conta distinta das moedas emitidas por governos soberanos, e não se caracterizam dispositivo ou sistema eletrônico para armazenamento em reais.

Noutro giro, está em tramitação na Câmara dos Deputados o PL 2.303/2015 ${ }^{10}$, de autoria do Deputado Federal Aureo ( $\mathrm{SD} / \mathrm{RJ})$, que "dispõe sobre a inclusão das moedas virtuais e programas de milhagem aéreas na definição de 'arranjos de pagamento' sob a supervisão do Banco Central" (altera a Lei no 12.865, de 2013 e a Lei 9.613, de 1998).

O projeto de lei 2.303/15 determina que as moedas virtuais devam ser disciplinadas pelo Banco Central e fiscalizadas pelo Conselho de Controle de Atividades Financeiras (COAF).

Porém, até então, tal projeto de lei ainda não foi votado pela Câmara, embora o Relator da Comissão Especial destinada a proferir parecer sobre o projeto de lei 2.303/15, Deputado Expedito Netto, em seu parecer, manifestou-se pela constitucionalidade, juridicidade, e adequação à técnica legislativa, bem como pela aprovação do projeto de lei $2.303 / 15$, com substitutivo ${ }^{11}$.

Atualmente, a Comissão Especial está aguardando a realização de nova reunião de Audiência Pública para esclarecimento sobre os temas ambiente virtual de jogos (off-shore) e arranjos de pagamento.

\footnotetext{
${ }^{10}$ O PL 2.303/15 tem a seguinte redação: Art. 1. Modifique-se o inciso I do art. 9 o da Lei 12.865, de 09 de outubro de 2013: "Art. $9 \circ$ (...) I - disciplinar os arranjos de pagamento; incluindo aqueles baseados em moedas virtuais e programas de milhagens aéreas;" Art. $2^{\circ}$. Acrescente-se o seguinte $₫ 4^{\circ}$ ao art.11 da Lei 9.613, de 03 de março de 1998: "Art. 11 (...), $\$ 4^{\circ}$ As operações mencionadas no inciso I incluem aquelas que envolvem moedas virtuais e programas de milhagens aéreas” Art. 3. Aplicam-se às operações conduzidas no mercado virtual de moedas, no que couber, as disposições da Lei no 8.078, de 11 de setembro de 1990, e suas alterações. Art. $4^{\circ}$ Esta Lei entra em vigor na data de sua publicação.

11 O inteiro teor do Parecer do Relator Dep. Expedito Netto pode ser consultado em <http://www.camara.gov.br/proposicoesWeb/prop_mostrarintegra;jsessionid=5E9E2A8579A0A756AF18BED2F022791A.pro posicoesWebExterno1?codteor=1632751\&filename=Parecer-PL230315-13-12-2017>. Acesso em 11 mar. 2018.
} 


\section{OS PRINCIPAIS OBJETIVOS DA RECUPERAÇÃO JUDICIAL ATINENTES A LEI $11.101 / 05$ (LEI DE RECUPERAÇÃO E FALÊNCA - LREF)}

Em 09 de fevereiro de 2005, foi sancionada a Lei n. 11.101, popularmente conhecida como Lei de Recuperação e Falência (LREF), que regula a falência, recuperação judicial e recuperação extrajudicial do empresário e da sociedade empresária. A Lei n. 11.101 substituiu o antigo Decreto-Lei n. 7.661/45, legislação que trazia o instituto da Concordata (PATROCÍNIO, 2013, p. 6-7).

Isto se deu, pois o instituto da Concordata previsto no Decreto-Lei n. 7.661/45 não mais atendia aos interesses do devedor e dos demais conectados à empresa, ou seja, a Concordata não atendia mais às finalidades que ensejaram sua adoção no Direito Brasileiro (CAMPOS FILHO, 2007, p. 19).

Desta forma, conforme o art. $1^{0}$ da LREF $^{12}$, apenas o empresário ${ }^{13}$, a empresa individual de responsabilidade limitada (EIRELI) e a sociedade empresária se sujeitam ao regime previsto na LREF, sendo que a ela não se sujeitam os agentes econômicos que exerçam atividade de natureza intelectual (PATROCÍNIO, 2013, p. 9-10).

No que tange à recuperação judicial, esta se caracteriza por ser uma medida judicial através da qual o devedor, desde que comprove a presença de determinados requisitos previstos na Lei 11.101/95, será autorizado a apresentar um plano de recuperação, que deverá ser aprovado pelos credores, para, em determinado tempo, compor suas obrigações junto a estes (GUIMARÃES, 2008, p. 234).

Conforme expõe Daniel Moreira do Patrocínio,

Para as empresas que se encontrem em crise econômico-financeira passível de superação, previu nosso legislador a possibilidade de implementação de um plano formulado pelo devedor empresário, desde que aprovado por seus credores. Essa recuperação da empresa foi instituída diante da constatação da relevância de seu papel em nossa sociedade, sua importância para os empregados, o fisco, seus fornecedores e a comunidade onde está inserida, não se restringindo apenas à satisfação dos interesses de seus sócios (PATROCÍNIO, 2013, p. 1).

Em tese, a recuperação judicial seria o instituto jurídico fundado na ética da solidariedade, para sanar o estado de crise econômico-financeira do empresário e da sociedade empresária, para preservar os negócios sociais e estimular a atividade empresarial, assegurar a continuidade do emprego e fomentar o trabalho humano, continuar a satisfação, mesmo que parcial e em diferentes condições e proporções, dos direitos e interesses dos credores, além de impulsionar a economia creditícia, mediante a apresentação, nos autos da recuperação judicial,

\footnotetext{
${ }^{12}$ Art. $1^{\circ}$ da LREF - Esta Lei disciplina a recuperação judicial, a recuperação extrajudicial e a falência do empresário e da sociedade empresária, doravante referidos simplesmente como devedor.

${ }^{13}$ De acordo com o art. 966 do Código Civil, empresário é o profissional que exerce atividade econômica organizada para a produção ou a circulação de bens ou de serviços.
} 
de um plano de reestruturação e reerguimento.

Importante destacar que não será qualquer empresário individual ou sociedade empresária que se encontre em situação de crise econômico-financeira que terá direito à recuperação judicial, mas apenas aquelas com possibilidade de superação. Quanto aos empresários e sociedades empresárias que se encontram em situação de crise econômico-financeira de natureza insuperável, devem ter a sua falência decretada, para não prejudicarem o bom andamento das relações econômicas do mercado (BEZERRA FILHO, 2009, p. 123).

Logo, "se não há solução de mercado para a crise de determinada empresa, é porque ela não comporta recuperação" (COELHO, 2010, p. 130).

Destarte, conforme preleciona o art. 47 da LREF, a recuperação judicial tem por objetivo viabilizar a superação da situação de crise econômico-financeira do devedor, a fim de permitir a manutenção da fonte produtora, do emprego dos trabalhadores e dos interesses dos credores, promovendo, assim, a preservação da empresa, sua função social e o estímulo à atividade econômica.

Em relação à superação da crise econômico-financeira, Daniel Moreira do Patrocínio (2013, p. 85) ensina que esta só será concretizada se a recuperação for concedida em favor de sociedades empresárias que sejam capazes de transpor o episódio de instabilidade nas relações jurídicas mantidas para o exercício de suas atividades negociais. Em outras palavras, para a superação da crise econômico-financeira, a sociedade empresária deve ser recuperável, motivo pelo qual a concessão da recuperação em favor de sociedades irrecuperáveis viola a superação da crise econômico-financeira.

Para tanto, isto é, para saber se a sociedade empresária é recuperável, importante saber se os custos que serão incorridos para que as suas relações contratuais sejam, novamente, estabilizadas são menores do que aqueles decorrentes da decretação da quebra (PATROCINIO, 2013, p. 86-87).

Bezerra Filho defende que a recuperação judicial possui uma ordem de prioridades, colocando como primeiro objetivo a manutenção da fonte produtora para, só então, satisfazer os interesses dos credores (BEZERRA FILHO, 2009, p. 123).

Neste diapasão, a manutenção da fonte produtora pressupõe a manutenção das relações jurídicas que gravitam em torno da sociedade empresária em crise, inclusive as relações trabalhistas, tendo em vista que a simples realização do ativo do devedor e satisfação dos créditos dos credores não seria adequado.

Para Daniel Moreira do Patrocínio, a manutenção da fonte produtora tem como consequência a preservação da empresa, que contribui para a continuidade da exploração dos fatores de produção organizados (PATROCÍNIO, 2013, p. 89). 
Desta forma, a empresa ${ }^{14}$ deve ser preservada, tendo em vista que esta, nas palavras de Fazzio Junior (2005, p. 35), "é uma unidade econômica que interage no mercado, compondo uma labiríntica teia de relações jurídicas com extraordinária repercussão social. É uma unidade de distribuição de bens e/ou serviços".

O Autor completa, ao dizer que a empresa "é um ponto de alocação de trabalho, oferecendo empregos. É um elo na imensa corrente do mercado que, por isso, não pode desaparecer" (FAZZIO JUNIOR, 2005, p. 35).

Uma vez alcançados os objetivos da recuperação judicial previstos no art. 47 da LREF, consequentemente, a empresa cumprirá a sua função social, eis que com a atividade econômica da sociedade empresária em funcionamento, fomenta-se a economia do país, proporcionando-se acúmulo de parceiros comerciais, clientes e prestadores de serviços, mais empregos são gerados, mais tributos são recolhidos, etc. Afinal, a atividade empresária açambarca em seu funcionamento a atuação de distintos grupos de pessoas, sendo eles empregadores, sócios, administradores, prestadores de serviços, fornecedores, empregados, clientes, etc. Almeja-se tutelar todos que lidam com a empresa.

Logo, para cumprir sua função social, o exercício da atividade empresarial não pode desprezar os interesses das diversas pessoas que gravitam ao seu redor, como o fisco, seus fornecedores, empregados, outros empresários, enfim, de toda a comunidade na qual a empresa se encontra inserida (PATROCÍNIO, 2013, p. 101102).

Portanto, para alcançar os objetivos da recuperação judicial previstos no art. 47 da LREF e, consequentemente, afastar a situação de crise econômico-financeira, mister ponderar sobre a pertinência de utilização da aplicação da Análise Econômica do Direito, no intuito de reduzir os custos de transação e aumentar os resultados, alcançando-se maior eficiência na recuperação judicial.

\section{A PERTINÊNCIA DA UTILIZAÇÃO DO BITCON EM TRANSAÇÕES REALIZADAS PELA SOCIEDADE EMPRESÁRIA EM RECUPERAÇÃO JUDICIAL}

O próprio art. 47 da LREF, como acima salientado, indica os objetivos da recuperação judicial, quais sejam viabilizar a superação da situação de crise econômico-financeira e patrimonial, preservação da atividade econômica e dos seus postos de trabalho, bem como o atendimento aos interesses dos credores, no intuito de que a empresa se recupere e cumpra a sua função social (COELHO, 2010, p. 127-128).

Assim, para manter sua fonte produtora e preservar sua atividade econômica, o empresário, para exercer a atividade empresarial, celebra contratos com fornecedores e consumidores. Afinal, o exercício da atividade

${ }^{14}$ A terminologia empresa, neste contexto, é usada como objeto, atividade empresária. 
empresarial pressupõe a existência de diversos contratos, tais como, exemplificativamente, de aluguel, os contratos trabalhistas, prestação de arte gráfica de marcas e embalagens, preservação dos equipamentos necessários ao exercício da atividade empresarial, financiamentos e empréstimos bancários para aquisição de equipamentos e matérias-primas, além de obrigações legais, tais como as obrigações tributárias.

Desta forma, após a apresentação do plano de recuperação e eventual aceitação pelos credores, o empresário ou a sociedade empresária precisam continuar celebrando contratos com fornecedores e consumidores. Afinal, a empresa deve preservar a sua atividade econômica.

Logo, os bitcoins podem contribuir, e muito, para que a sociedade empresária consiga alcançar os objetivos da recuperação judicial, reduzindo os custos de transação e alcançando a eficiência, conforme ensinamentos da Análise Econômica do Direito.

Isto, pois os bitcoins possuem algumas peculiaridades que, quer queira ou quer não, são vistas como vantagens nas relações contratuais e no mercado empresarial, fazendo com que a devedora e seus credores consigam alcançar maior eficiência, promovendo, assim, a preservação da empresa, sua função social e o estímulo à atividade econômica.

E mais, como já salientam Eduardo Goulart Pimenta e Stefano Boglione, a Análise Econômica do Direito se preocupa com "a obtenção de eficiência nas relações entre os agentes e com a alocação ótima dos recursos. Essas relações se institucionalizam através dos contratos" (PIMENTA; BOGLIONE, 2013, p. 271).

Neste sentir, o bitcoin, por ser moeda virtual, pode ser utilizado como forma de pagamento nos contratos celebrados pelo empresário com terceiros, sejam estes fornecedores ou consumidores, bem como ser utilizado como forma de auxiliar o meio de recuperação judicial escolhido para o plano de recuperação apresentado pelo empresário.

E, partindo do pressuposto de que o rol previsto no art. 50 da Lei $11.101 / 05^{15}$, que traz alguns meios de recuperação judicial, é um rol exemplificativo, o administrador judicial possui a liberdade de incluir os bitcoins ou permitir transações envolvendo bitcoins no plano de recuperação judicial, como um meio de recuperação.

Além disso, os bitcoins podem ser utilizados nos novos contratos celebrados entre a recuperanda e terceiros, antes ou após a aprovação do plano de recuperação judicial.

Conforme acima salientado, os bitcoins possuem vantagens que podem beneficiar os seus usuários, vantagens estas que não ocorrem com papel-moeda, ouro, cartão de crédito ou PayPal. Nas palavras de Natasha Alves Ferreira:

Os pagamentos com bitcoins funcionam como os cartões de credito ou débito, mas sem a

\footnotetext{
${ }^{15}$ Vide o rol exemplificativo do artigo 50 da lei 11.101/05.
} 
necessidade de ter uma conta bancária. Uma das principais vantagens é a possibilidade de enviar e receber instantaneamente as bitcoins, em qualquer parte do mundo e a qualquer tempo. Além disso, as taxas são muito baixas ou até inexistentes, podendo os usuários incluírem uma taxa nas suas transações para receber a prioridade no processamento. As transações são realizadas de forma mais rápida e mais barata do que com os meios tradicionais de pagamento. As taxas de transação, quando existem, são muito baixas e não há taxa de conta bancária a ser cobrada. Outra vantagem é que as transações com Bitcoins são irreversíveis e não contêm dados pessoais ou privados dos clientes. Dessa forma, as transações podem ser feitas sem vinculação de informação pessoal. Assim sendo, existe uma forte proteção contra o roubo de identidade. Também é impossível que comerciantes efetuem cobranças indesejadas ou imperceptíveis aos usuários, como pode acontecer em outras formas de pagamento. Ademais, os usuários podem proteger seu dinheiro através de backup e criptografia. As informações sobre Bitcoins estão disponíveis no block chain para que qualquer pessoa possa verificá-las e utilizá-las em tempo real. Ainda, por ser criptograficamente seguro, nenhum indivíduo ou organização pode controlar ou manipular o protocolo Bitcoin. Isso permite que seu núcleo seja confiável, neutro, transparente e previsível (FERREIRA, 2014, p. 384).

Assim, de acordo com Fernando Ulrich, "é na redução dos custos de transação, porém, que entendemos as enormes vantagens e superioridade do Bitcoin" (ULRICH, 2016, p. 99), ou seja, a redução dos custos de transação está nas vantagens do bitcoin, fazendo com que ele seja superior às demais moedas, como o ouro ou papel-moeda.

Sobre as vantagens do bitcoin, aduz o autor:

Para começar, não há fronteiras políticas à moeda digital. Você pode enviar e receber Bitcoins de qualquer lugar a qualquer pessoa, esteja ela onde estiver, sem ter que ligar ao gerente do banco, assinar qualquer papel, comparecer a alguma agência bancária ou ATM. Nem mesmo precisa usar VISA ou PayPal. Você pode ter domicílio no Brasil, estar de férias em Xangai e enviar dinheiro a uma empresa na Islândia com a mesma facilidade com que envia um e-mail pelo seu iphone. Ainda em Xangai, você pode receber em bitcoins o equivalente a quilos de prata (ou outro, ou milhares de dólares), sem pesar um grama no seu bolso, nem mesmo precisar contar as suas cédulas ou pesar o seu metal. Tampouco precisa se preocupar em guardá-lo em algum armazém ou banco (ULRICH, 2016, p. 99).

Neste diapasão, de acordo com Tatiana Casseb Bahr de Miranda Barbosa,

Por outro lado, como ponto positivo há o fato destas transações serem transnacionais, não estando sujeitos à interferência do Estado ou mesmo tributação e encargos pela utilização destas moedas. Ademais, outras características se sobressaem, como as taxas de transações praticamente nulas, a segurança, a proteção contra fraude, a velocidade das negociações e a privacidade são algumas das características marcantes da criptomoeda (BARBOSA, 2016, p. 263).

Como não há um terceiro intermediário, as transações de bitcoins são mais baratas e rápidas do que as feitas por redes de pagamentos tradicionais, motivo pelo qual o bitcoiné uma grande promessa de uma forma de reduzir os custos de transação. Como o bitcoin facilita transações diretas sem um terceiro, ele remove cobranças custosas que acompanham as transações com cartões de crédito, por exemplo (ULRICH, 2014, p. 23).

Ora, se o bitcoin remove as cobranças custosas das transações, consequentemente haverá redução nos custos de transação durante a recuperação judicial e, havendo a redução dos custos de transação, as transações 
serão mais fáceis e acessíveis, motivo pelo qual, acredita-se ser pertinente afirmar que o bitcoin também facilita as transações.

Quando algum empresário opta por aceitar pagamentos com cartão de crédito, por exemplo, este vem acompanhado de pesados custos. Isto, pois para aceitar pagamentos por cartão de crédito, o comerciante precisa contratar uma conta com as empresas de cartões e, não raro, pagar taxas de autorização, taxas de transação, taxas de extrato, etc. Essas taxas se acumulam e aumentam significativamente o custo da empresa. Assim, como o bitcoin facilita as transações sem um terceiro intermediário, ele remove as cobranças custosas que acompanham os cartões de crédito (ULRICH, 2014, p. 23-24).

E mais, não ter que pagar taxas às instituições financeiras e companhias de cartões de crédito significa que os comerciantes podem repassar as economias aos preços finais ao consumidor (ULRICH, 2014, p. 24).

Logo, ao realizar transações no mercado bitcoin, seja pagando ou recebendo bitcoin, o empresário terá menor custo de transação e, quanto mais pessoas adotarem esta forma de transação, menores serão os custos monetários finais.

Conforme Eduardo Goulart Pimenta, as transações econômicas, ou relações contratuais, são instrumentos pelos quais os agentes econômicos procuram interagir no sentido de obter a máxima eficiência na produção ou alocação dos bens e serviços disponíveis, maximizando seus próprios interesses (PIMENTA, 2010, p.31).

Acerca da eficiência nas relações contratuais, Eduardo Goulart Pimenta aduz que:

A eficiência, aqui, está em permitir que estas transações se realizem com o menor custo possível. Quanto mais baixos forem os custos de transação maiores e eficientes serão as transações contratuais [...]. Sob este perfil a eficiência do Direito está em minimizar (ou, hipoteticamente, acabar) com os custos de transação - mediante redução ou eliminação das dificuldades e gastos para contratação - de forma que, no exercício da empresa, haja uma maior quantidade e qualidade de trocas e relações jurídicas destinadas à organização dos fatores de produção (PIMENTA, 2010, p. 33).

Portanto, entende-se, de forma construtiva, sem pretender esgotar o assunto, que os bitcoins, quando utilizados, ajudam a reduzir os custos de transação e, consequentemente, colaboram para aumentar a eficiência nas relações econômicas, maximizando os lucros e resultados.

Importante destacar que o bitcoin ainda é uma moeda nova e flutuante que, por ser desconhecida, não é aceita por muitos comerciantes e empresários, tornando seu uso quase experimental. Para entender melhor o bitcoin, ajuda se pensarmos que ele não é um substituto às moedas tradicionais (real, dólar, ouro), mas sim um novo sistema de pagamentos (ULRICH, 2014, p. 23).

Com isso, o empresário ou a sociedade empresária em recuperação poderão reduzir seus custos de transação e aumentar a eficiência, alcançando todos os objetivos da recuperação judicial, quais sejam, viabilizar a 
superação da situação de crise econômico-financeira do devedor, manutenção da fonte produtora, bem como do emprego dos trabalhadores e dos interesses dos credores, promovendo, assim, a preservação da empresa, sua função social e o estímulo à atividade econômica.

\section{CONCLUSÃO}

Portanto, de acordo com a Análise Econômica do Direito, quando da celebração dos negócios jurídicos, as partes devem sempre buscar a redução dos custos de transação e a maximização dos resultados, alcançando-se a tão almejada eficiência.

Desta maneira, os bitcoins foram criados para: a) dar celeridade e facilitar as transações; b) eliminar a necessidade de terceiros intermediários para qualquer transação, seja este terceiro um banco ou uma autoridade estatal; c) dar segurança às transações; e d) reduzir os custos.

Assim, em razão das suas vantagens, os bitcoins podem ser utilizados nas relações jurídicas celebradas entre as partes, tendo em vista que o rol previsto no artigo 50 da lei 11.101/05 é exemplificativo.

Com isso, não será necessária uma instituição financeira para realizar a intermediação entre os contratantes, acarretando em menor custo monetário e de transação, proporcionando maior celeridade entre as transações negocias, em prol da eficiência, imprescindíveis para que a atividade em recuperação supere sua crise econômica, financeira ou patrimonial.

Em outras palavras, acredita-se que é pertinente afirmar que com os bitcoins e as suas vantagens, os agentes, durante o processo de recuperação, conseguirão reduzir os custos de transação, acarretando em maiores benefícios, alcançando-se, assim, a eficiência, conforme preconiza a AED. Consequentemente, a sociedade empresária em recuperação terá, em tese e em princípio, mais lucro.

Assim, o empresário ou sociedade empresária que esteja em recuperação judicial poderá realizar transações com bitcoins, sejam transações com consumidores, fornecedores ou terceiros, bem como celebrar novos contratos em que a contraprestação seja em bitcoins.

E, com maior eficiência, permite-se que a recuperação judicial cumpra todos os objetivos previstos no art. 47 da LREF, quais sejam, viabilizar a superação da situação de crise econômico-financeira do devedor, manutenção da fonte produtora, do emprego dos trabalhadores e dos interesses dos credores, promovendo, assim, a preservação da empresa, sua função social e o estímulo à atividade econômica.

Ademais, maximizando os lucros e alcançando a eficiência nas relações contratuais, com os bitcoins, a empresa em recuperação poderá realizar novas transações e celebrar novos contratos, bem como expandir sua atuação no mercado, de modo a se soerguer, afastando a situação de crise econômico-financeira. 


\title{
SOME REFLECTIONS AND RELEVANT WEIGHTS, VIA THE ECONOMIC ANALYSIS OF LAW, ON BITCOINS AND THEIR EVENTUAL USE IN JUDICIAL RECOVERY
}

\begin{abstract}
In an academic and constructive way, without intending to exhaust the subject, this research aims to carry out a legal and economic study of bitcoin, which is the most used virtual currency in the world, through the methodological tools of Economic Analysis of Law, demonstrating how the use of bitcoins in transactions carried out by the recovering company can reduce transaction costs and contribute to a less costly, faster and more efficient judicial recovery, also helping to ensure judicial recovery meets its objectives Art. 47 of Law no. 11.101 / 05 , which is to make it possible to overcome the economic and financial crisis of the debtor, the maintenance of the source, as well as the employment of workers and the interests of creditors, thus promoting the preservation of the company, its social function and stimulating economic activity.
\end{abstract}

Keywords: Bitcoins. Economic Analysis of Law. Transaction costs.

\section{REFERÊNCIAS BIBLIOGRÁFICAS}

ALVAREZ, Alejandro Bugallo. Análise Econômica do Direito: Contribuições e Desmistificações. Disponível em: <http://direitoestadosociedade.jur.puc-rio.br/media/Bugallo_n29.pdf>. Acesso em: 22 ago. 2017.

BARBOSA, Tatiana Casseb Bahr de Miranda. Regulamentação Internacional de Moedas Digitais. In: BARBOSA, Tatiana Casseb Bahr de Miranda (coord.). A Revolução das Moedas Digitais: Bitcoins e Altcoins. Aspectos Jurídicos, Sociológicos, Econômicos e da Ciência da Computação. 1a edição. São Paulo: Editora Revoar, 2016.

BEZERRA FILHO, Manoel Justino. Lei de Recuperação de Empresas e Falências Comentada. 6a ed. São Paulo: Revista dos Tribunais. 2009.

BRASIL. Banco Central do Brasil. Comunicado n. 25.306, de 19 de fevereiro de 2014. Disponível em: <https://www3.bcb.gov.br/normativo/detalharNormativo.do?method=detalharNormativo\&N=114009277>. 
Acesso em: 22 out. 2017.

CAMPOS FILHO, Moacyr Lobato. Falência e Recuperação. 1ª ed. Belo Horizonte: Del Rey. 2007.

COASE, Ronald H. O Problema do Custo Social. 1960. Disponível em: <http://www.pucpr.br/arquivosUpload/5371894291314711916.pdf>. Acesso em: 28 ago. 2017.

COELHO, Fábio Ulhoa. Comentários à Lei de Falências e de Recuperação de Empresas. 7a ed. São Paulo: Saraiva. 2010.

COOTER, Robert; ULEN Thomas. Direito \& Economia. 5a ed. Tradução: Luis Marcos Sander, Francisco Araújo da Costa. Porto Alegre: Bookman. 2010.

FAZZIO JÚNIOR, Waldo. Nova Lei de Falência e Recuperação de Empresas. 2a ed. São Paulo: Atlas. 2005.

FERREIRA, Natasha Alves. Incertezas Jurídicas e Econômicas da Bitcoin Como Moeda. In: CONPEDI/UFPB. (Org.). Direito e economia II. 1ª edição. Florianópolis: CONPEDI, 2014, p. 380-406.

GUIMARÃES, Leonardo. Documentos a Serem Acostados, Obrigatoriamente, à Petição Inicial da Recuperação Judicial. In: CASTRO, Moema A. S. de; CARVALHO, William Eustáquio de (Coord.). Direito Falimentar Contemporâneo. Porto Alegre: Sergio Antonio Fabris Editor, 2008.

LANA, Henrique Avelino. Dissolução parcial nas sociedades limitadas: Análise econômica sobre a inclusão do aviamento na apuração de haveres. Belo Horizonte: Arraes Editores. 2012;

Falência e Recuperação de Empresas: Análise econômica do direito. Belo Horizonte: Editora D’Plácido. 2017;

Sociedades Limitadas: Uma Leitura Via Law And Economics. In: SCIENTIA IURIS, Londrina, v. 18, n. 1, p. 9-43, jul. 2014.2 Disponível em: <http://www.uel.br/revistas/uel/index.php/iuris/article/viewFile/15206/14724>. Acesso em: 10 mar. 2018.

MANKIW, Gregory. Princípios de Microeconomia. Tradução: Allan Vidigal Hastings. São Paulo: Cengage Learning. 2009. 
NAKAMOTO, Satoshi, Bitcoin: A Peer-to-Peer Electronic Cash System. Disponível em $<$ https://bitcoin.org/bitcoin.pdf>. Acesso em: 22 ago. 2017.

PATROCÍNIO, Daniel Moreira do. Análise Econômica da Recuperação Judicial de Empresas. Rio de Janeiro: Lumen Juris. 2013;

Recuperação de Empresas e Falência: Lei e Jurisprudência. Rio de Janeiro: Lumen Juris. 2013.

PIMENTA, Eduardo Goulart. Direito Societário. Campus Jurídico. Rio de Janeiro: Campus Jurídico. 2010.

PIMENTA, Eduardo Goulart; BOGLIONE, Stefano. Princípios e Conceitos Fundamentais da Análise Econômica do Direito. In: MARÇAL; Antônio Cota; PIMENTA; Eduardo Goulart; NUNES, Maria Emília Naves; MAGALHÃES, Rodrigo Almeida (Org.). Os Princípios na Construção do Direito. Rio de Janeiro: Lumen Juris, 2013.

PIMENTA, Eduardo Goulart; LANA, Henrique Avelino Rodrigues de Paula. Análise Econômica do Direito e Sua Relação Com o Direito Civil Brasileiro. In: Revista da Faculdade de Direito da Universidade Federal de Minas Gerais. n. 57.p. 85-138. Belo Horizonte: jul/dez. 2010.

PINHEIRO, Armando Castelar. Direito e economia num mundo globalizado: cooperação ou confronto? Direito e economia. São Paulo: IOB Thomson, 2005.

PINHEIRO, Armando Castelar; SADDI, Jairo. Direito, economia e mercados. São Paulo: Elsevier Campos. 2005.

RIBEIRO, Márcia Carla Pereira; GALESKI, Irineu Júnior. Teoria Geral dos Contratos. Contratos Empresariais e análise econômica. Rio de Janeiro: Elsevier. 2009.

RIO DE JANEIRO, Assembleia Legislativa. Projeto de Lei Projeto de Lei no 2303, de 2015. Dispõe sobre a inclusão das moedas virtuais e programas de milhagem aéreas na definição de "arranjos de pagamento" sob a $\begin{array}{lllll}\text { supervisão } & \text { do } & \text { Banco } & \text { Dentral. }\end{array}$ <http://www.camara.gov.br/proposicoesWeb/prop_mostrarintegra;jsessionid=AA3E371B386A691BCD9E34 4B47D0DED5.proposicoesWebExterno 1?codteor=1358969\&filename=PL+2303/2015>. Acesso em: 21 out. 
SALAMA, Bruno Meyerhof. O Que é “Direito e Economia”? In: TIMM, Luciano Benetti (Org.). Direito \& Economia. 2a edição. Porto Alegre: Livraria do Advogado, 2008;

SILVA, Alexandre Pacheco da. Oportunidades e Oportunismos: As Dimensões Internas e Externas de Segurança do Bitcoin. In: BARBOSA, Tatiana Casseb Bahr de Miranda (coord.). A Revolução das Moedas Digitais: Bitcoins e Altcoins. Aspectos Jurídicos, Sociológicos, Econômicos e da Ciência da Computação. 1a edição. São Paulo: Editora Revoar, 2016.

SZTAJN, Raquel. Law \& Economics. In: SZTAJN, Raquel; ZYLBERSZTAJN, Décio (Org.). Direito e Economia. Análise econômica do direito e das organizaçôes. Rio de Janeiro: Elseivier. 2005.

SZTAJN, Raquel; ZYLBERSZTAJN, Décio. Direito e Economia: Análise econômica do direito e das organizações. Rio de Janeiro: Ed. Campus. 2005;

ULRICH, Fernando. Aspectos Econômicos do Bitcoin. In: BARBOSA, Tatiana Casseb Bahr de Miranda (coord.). A Revolução das Moedas Digitais: Bitcoins e Altcoins. Aspectos Jurídicos, Sociológicos, Econômicos e da Ciência da Computação. 1a edição. São Paulo: Editora Revoar, 2016.

Bitcoin - A Moeda na Era Digital. Instituto Ludwig Von Mises Brasil. São Paulo: 2014.

Trabalho enviado em 01 de maio de 2018

Aceito em 31 de julho de 2018 